\title{
Resettling Muslim women with convictions
}

Sofia Buncy from Muslim Women in Prison, Sarah Goodwin from Sheffield Hallam University and Alexandria Bradley from Leeds Beckett University share some early findings from their research which is exploring Muslim women's experiences of

resettlement.
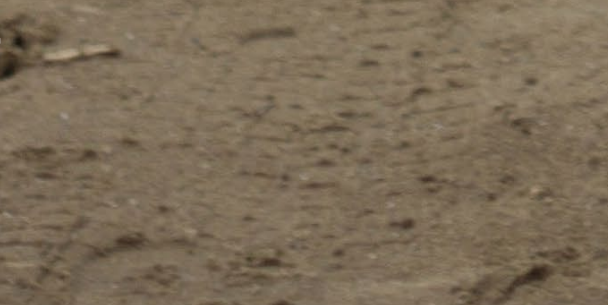
In 2021, Her Majesty's Inspectorate of Probation published a damning report citing the lack of effective work to address legacies of institutionalised racism within Probation Services and the resultant disparities in treatment of 'BAME' individuals (HMIP, 2021). Nevertheless, interest in providing appropriate services to Black, Asian and specific minoritised groups within the criminal justice system has been growing over the last few years. One such group is Muslim women. While a diverse group in many ways, they share some broad commonalities through the practice of their faith, share experiences of institutional racism and are an identifiable minoritised group within the system. Numbers are not very large, and at $7 \%$ of the female prison estate, the proportion of Muslim women is reflected in the general population (MoJ, 2021). Yet at any one time there are around 220 women in prison in England and Wales who identify as Muslim (MoJ, 2021). Practice must therefore be ready to support these women appropriately according to their particular needs, in line with legal obligations under the Equality Act 2010.

Despite some good practice examples, Black, Asian and minoritised women can be difficult for practitioners to cater for due to their relative invisibility within the system. Official probation statistics do not even currently publish the numbers of people on their caseload who are both female and Muslim. Policy reports which occasionally examine certain minoritised groups point to the distinct nature of needs and experiences within the criminal justice system but rarely have the scope to distinguish the specifics for any particular minoritised group, instead focusing on broad shared experiences of discrimination (Cox and Sacks-Jones, 2017; Shingler and Pope, 2018).

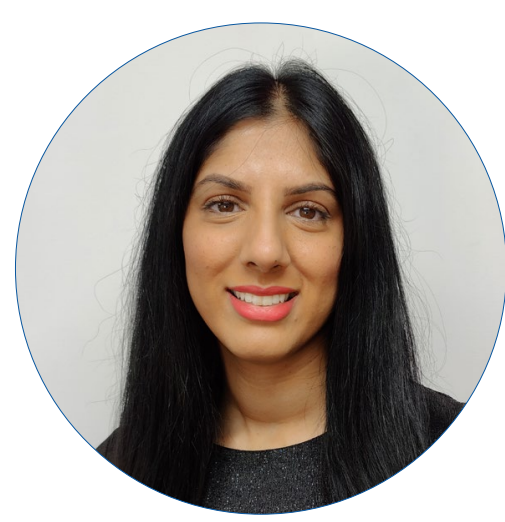

Sofia Buncy

Muslim Women in Prison

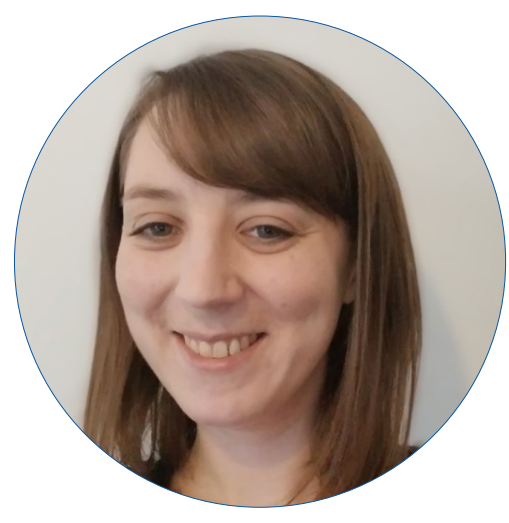

Sarah Goodwin

Sheffield Hallam University

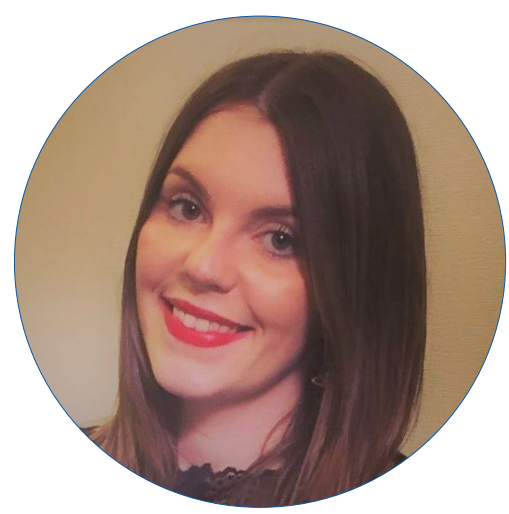

Alexandria Bradley Leeds Beckett University 
Academic research has begun to investigate minoritised experiences of desistance but thus far has not produced any work into Muslim women specifically. As a result, there is very little robust evidence about how to support Muslim women through the criminal justice system. It is therefore unsurprising that a focused engagement with understanding the needs and experiences of this group is lacking.

In 2021 we embarked on a project to fill this knowledge gap. Our collaboration between academics and practitioners is focused on understanding Muslim women's experiences of moving on from crime to support the development of effective policy and practice. The team comprises Sofia Buncy as national lead for the Muslim Women in Prison project, and two academics - Alexandria Bradley and Sarah Goodwin - with research expertise in women's experiences in prison and of desistance. We have completed our initial pilot stage having interviewed 5 Muslim women based in Yorkshire twice each. We are now developing a larger, national, study but there are some important findings already emerging from the pilot data. Here we share an outline of those findings, along with some suggestions of how to translate these into good practice.

The first of these findings centres around the elevated importance of shame in participants' experiences of desisting from crime. While shame is often recognised as particularly important to women's desistance (Rutter and Barr, 2021; Gålnander, 2020), the Muslim women who worked with us reported particularly acute encounters of shame. This had implications on how they coped emotionally with their situations, what they did with their days and who they interacted with. However, even where immediate families remained supportive, it also had significant consequences for the participants' wider families, with mothers, children and cousins being harassed or shunned for the shame the participants were deemed to have caused. An awareness in shame and how it may broadly impact on practice is no doubt generally useful, but there is a very useful specific implication for women from certain minoritised groups. In our research, all the women spoke of the importance to them, or other Muslim women in the criminal justice system that they knew personally, of relocating away from their family home or local communities. For some, the shame is so intense - either in individual consequences or the consequences to the extended family - that it was necessary to relocate to another city, or part of a city, in order to avoid it. These women wanted to move somewhere that they were not known, so that they could avoid being stopped and berated on the street or whispered about in the halal butchers. They wanted to shield their children from bullying at school and protect their mothers and extended family from gossip. It was only with a fresh start that they could think about moving forward with their lives. 
Relocation is sometimes mentioned in the academic and policy literature but it is rarely centred, with maintaining local family connections instead prioritised. Yet the early indications from our research are that relocation is a common desire among Muslim women in the criminal justice system, even where they enjoy a warm and supportive relationship with their families.

So what can practitioners do, knowing the potential impact of shame and the desire to relocate among Muslim women?

- Be aware of the potential impact of an extended family and wider community viewing a client as bringing shame to the family or community. Ask clients about their relationships with extended family and local community.

- Be aware of the potential social challenges and associated difficulties brought by shame which may face a Muslim women should she choose to return to her community.

- Be aware that a family may be supportive and that a client may still wish to move away from them at the same time, for good reasons.

- Remember that relocation might be a high priority for a Muslim woman. Ask if they feel it would be helpful in their situation.

- It may be unusual for you to facilitate a move between areas for clients. Look into the practicalities of enabling this in terms of housing, probation, schools and support services. This will mean you are less likely to be taken by surprise should a client request a relocation.

\section{References}

Cox, J. and Sacks-Jones, K. (2017) “Double Disadvantage" The Experiences of Black, Asian and Minority Ethnic Women in the Criminal Justice System. Agenda and Women in Prison.

Gålnander, R. (2020) "Shark In the Fish Tank': Secrets and Stigma In Relational Desistance From Crime'. The British Journal of Criminology. 60 (5), pp. 1302-1319.

Her Majesty's Inspectorate of Probation. (2021) Race equality in probation: the experiences of black, Asian and minority ethnic probation service users and staff, Available at: https://www.justiceinspectorates.gov.uk/ hmiprobation/wp-content/uploads/sites/5/2021/03/ Race-Equality-in-Probation-thematic-inspectionreport-v1.0.pdf (Downloaded: 20th May 2021).

Ministry of Justice. (2021a) Offender Management statistics quarterly: January to March 2021, Available at: https://www.gov.uk/government/statistics/ offender-management-statistics-quarterly-january-tomarch-2021 (Downloaded 20th September 2021)

Rutter, N. and Barr, U. (2021) 'Being a 'good woman': Stigma, relationships and desistance, Probation Journal, 68 (2), pp. 166-185.

Shingler, J and Pope, L. (2018) The Effectiveness of Rehab Services for BAME People: A Rapid Evidence Assessment. Ministry of Justice Analytical Series. 